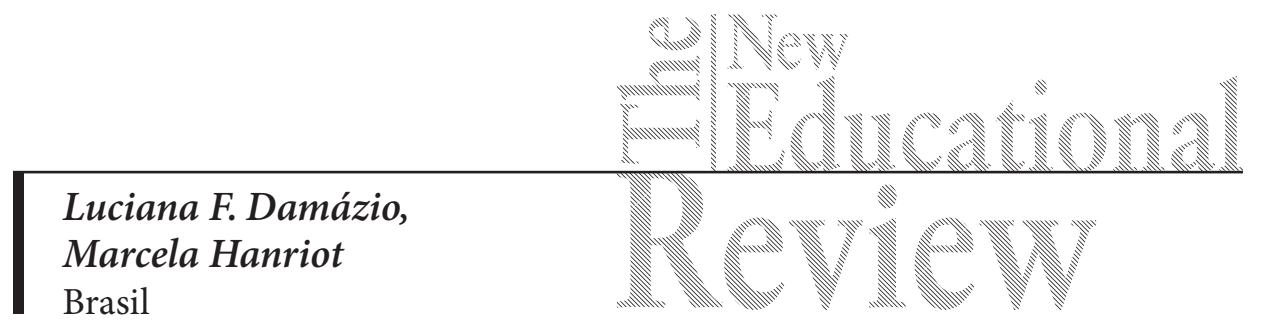

\title{
The Revision of a Marketing Course Using a Competency-Based Curriculum
}

DOI: 10.15804/tner.2017.48.2.03

\begin{abstract}
This paper presents the process of reviewing a lato sensu postgraduate course in marketing offered at a Brazilian business school. Changes were implemented to adapt the course to the job market demands. The results of the quantitative phase of the research showed that the course had many opportunities for improvement, especially regarding the course methodology. The results of the qualitative stage indicate an opportunity for improvement of the course contents by updating them and ensuring they adhere to professional practice. The redesign process of the course was based on the competency-based curriculum.
\end{abstract}

Keywords: higher education, competency-based curriculum, marketing education, business school

\section{Introduction}

With the rise of new technologies and new public and private institutions, more students with work experience are deciding to return to pursue higher education, and students' overall expectations are changing. Higher education institutions have faced many challenges over the past few years, as evidenced in the studies by Kinser and Levy (2005), Kirp (2009), Levy (2002, 2003, 2004, 2006, 2008) and Maringe and Gibbs (2009). "For-profit" private education has developed even in countries such as Brazil, where universities were traditionally federally operated. Presently, two-thirds of Brazil's private universities are for-profit. This is a global trend driven by the 
privatization of universities, and caused by, among many other factors, the inability of public institutions to meet the demand (Kinser and Levy, 2005).

As the number of new private institutions continues to increase, the competition between institutions (both public and private) increases. This competition modifies the education sector's dynamics in such a way that it becomes market oriented according to Levy $(2002,2003,2004,2006,2008)$. To survive, each institution needs to look for alternatives to outshine the others and to maximize their perceived value, which results in better customer loyalty and retention, leading to a stronger competitive position and, consequently, to a higher market share (Bearden and Teel, 1983; Fornell, 1992; Fornell et al., 1996). In order to accomplish this, the institutions need to develop practices that meet the current market demands.

A way to adapt an institution's courses to today's needs is to shift from traditional teaching and learning methodologies, in which "students...do not directly participate in the learning process" (Ryan and Martens, 1989, p. 20) to active learning, in which students are included in the learning process (Prince, 2004). The acknowledged adult learning psychology establishes the importance of active participation as well as the recognition of the adult's previous experience as a motivator in the learning process. In that sense, traditional teaching and learning methodologies are becoming decreasingly attractive to the public (Bonwell; Eison, 1991). The new challenge consists in incorporating the active methodologies of teaching and learning into the curriculum of higher education courses; especially in the lato-sensu postgraduate studies, which will be seen as a competitive advantage to the institutions.

\section{Research Problem}

In terms of postgraduate studies in the business administration area (more specifically, in the marketing sector), the challenge becomes even more relevant considering new business market dynamics, the environmental instability, and the amount of available information. These factors have transformed companies' market management into a much more complex activity. The "market dictatorship" requires continuous research on and analysis of market information by managers in order to create the best strategy and ensure the survival of their organizations (Danciu, 2013; Leeflang, Verhoef, Dahlström and Freundt, 2014). This research must be constant due to the large amount of information produced by the advance of information technology. As the rhythm of changes increases (Kotler, 2000), higher education institutions need to find alternative ways to incorporate into the classroom different strategies aimed to better teach their students. Strategies of active learning might help to attract students' interest (Bonwell, Eison, 1991). 
By bringing into the classroom the market's dynamic environment, the complexity of what should be discussed increases in terms of content, as well as how it should be discussed. Changes must be made regarding the methodological orientation; modernization of the field must include an unceasing improvement of the quality offered, which should aim at the formation of a professional better prepared to fit within this new context (Seung, Stepich and Cox, 2006). The use of new methods of teaching, such as the competency-based curriculum, is one of the ways to improve which type of content should be taught in higher education programs. With regard to how these contents may be delivered to the student, it is clear that educational institutions must be more objective and explicit than they were in the past. A complete experience must be designed in order for results to appear - the learning experience should start before the beginning of the actual course, and it must be extended until after the course is over (Pollock, Jefferson, Wick, 2015).

In order to enhance human capital in organizations, much has been discussed about the strategic importance of the learning process in business schools that offer postgraduate courses. A good strategy for learning helps to boost companies into a higher level of performance. Skills and knowledge acquired in these training courses need to be applied in favor of the organization. In order for that to happen, learning objectives must be connected to the expected results; that is, what will be expected for them to do at work, and the benefits of the newly gained knowledge, skill and ability to the business itself (Wick, Pollock, Jefferson and Flanagan, 2010).

The approach of the competency-based curriculum has been growing for several decades (Gillies and Howard, 2003; Gordon and Issenberg, 2003; James, 2002). It responds well to the need for enhancing human capital in organizations. It also constitutes a way to stimulate learning, since the competency-based curriculum aims to ensure that learners will be capable of demonstrating their learned skills after they have acquired a combination of knowledge, skills, and abilities (Seung Youn, Stepich and Cox, 2006).

\section{Research Focus}

Incorporating updated and innovative material into the curriculum and implementing leading educational methodologies have proven to be the greatest challenge for managers of higher education institutions. Usually, the higher education format is organized by passive learning through traditional disciplines, which does not take a systemic perspective and the learning process is fragmented. Therefore, the result is an unprepared professional to meet the cooperative efforts (Cortese, 2003). In business schools that offer lato sensu postgraduate courses, 
the focus must shift towards more innovative ways of learning since they need to follow market dynamics. In order to achieve that, methodologies applying an active approach might be more adequate, since they rely on the student's process of thinking as well as reading, analyzing and discussing everyday problems (Bonwell; Eison, 1991). If accomplished, the customer's perceived value of the business school increases. Programs intended for modernization of higher education must include a strategy that focuses on continuous improvement of the quality of the educational service provided by higher education institutions.

The general objective of this paper is to present the review process of a broad postgraduate course in marketing offered by a Brazilian business school, which aimed at the adequacy of content and methodological practices in order to better respond to market demands. The specific objectives are to investigate students' perception of the course methodological practices, learn about professors' perception of the contents that are taught during the course and acknowledge CEOs' perception of the necessary competences for a marketing professional in the current market environment, and also to present a new proposition of curriculum for a marketing course.

\section{$\underline{\text { Research Methodology }}$}

\section{Research General Background}

Considering the complexity of the subject, we chose to work with the triangulation of methods, which uses two different techniques, conducted in a complementary way, for the same research question. In order to accomplish this, we used two in-depth approaches: a quantitative approach, focusing on diagnosis, and a qualitative approach, exploring aspects more related to the construction of the proposal (Mertens, 2005).

In order to fully comprehend the object and the room for improvement in the postgraduate course, we chose to work with three different groups: former students, professors of the course offered by the Brazilian School, and CEOs of relevant companies in the county. The quantitative approach was used to learn from former students about the positive parts of our course, and which parts did not meet their expectations. The qualitative approach was used with both the professors of the course and the CEOs of important companies. The professors were asked to identify which contents were most important, in their point of view, to be taught to the students. The CEOs were told to think of which competences were most important for marketing managers to succeed in today's environment. 


\section{Quantitative Stage}

This approach aims to identify, as extensively as possible, the students' perception of methodological contents and practices developed by the postgraduate course (lato sensu) offered by an internationally accredited Brazilian business school.

A questionnaire was sent to 269 former students, who completed the program in the six months prior to the survey. A total of 80 completed questionnaires was received, equivalent to the return rate of $29.73 \%$. The questionnaires were created by the authors and pretested. The data was treated using descriptive statistics.

The questionnaire included 16 questions regarding the achievement of the proposed educational objectives, the methodological approach of the program, the extra-curricular activities, and results of the program.

\section{Qualitative Stage}

The qualitative approach investigated how executives and marketing professors set their professional practices to face the new challenges of this field of knowledge. The aim was to investigate possibilities for adaptation of the course in order to make it more adherent to the new market demands. In this case, the option to use a qualitative approach, which allows for further exploration of the topic, was chosen and the technique used was the focus group. This method creates conditions for participants' more spontaneous reaction and allows for a broader exploration of the subject (Stewart \& Shamdasani, 1991; Wan, Lee, \& Lee, 2007).

Two focus groups were then established in order to collect answers from both the executives and marketing professors. The first group consisted of 8 marketing executives of large companies and aimed at a more practical perspective; the second, involving 12 marketing professors from postgraduate courses, sought a more structured view of the subject.

To establish the first group, corporate executives from the marketing area, who had also completed an MBA program were invited. The second group consisted of marketing professors who taught subjects offered in a Brazilian latu sensu postgraduate program. Each focus group was mediated separately by one of the authors of this paper. In both cases, the purpose of the focus group was to identify the main challenges faced today by organizations in the area of marketing, and how those challenges are associated with the competences to be developed by the marketing manager.

The data collected from the focus groups were analyzed as follows: first, transcripts were generally studied in order to group the skills that contained convergent premises cited by the participants in the categories of analysis. The eidetic 
reduction - a method in which analyses of individual and concrete objects are made, the essence of which is extracted (Bednarski, 1962) - was used as an inspiration to extract the main meaning of the participants' lines. After that, a semantic equivalence board was drawn, containing six distinct categories identified from the participants' responses (Schwandt, 2000). Thus, it was possible to determine the frequency of citations in the analysis categories and define the most important competences for a marketer, according to the executives and professors, in the current scenario.

This methodological design made it possible to combine the ideas of the students, professors and executives in order to redesign and improve the course.

\section{Research Results}

\section{Quantitative Results}

The teaching objectives of the course were considered to be achieved taking into account the students' views, since those objectives had average scores greater than 3 on a 5 -point scale (Table 1). The average of all the assessed objectives was 3.65. Emphasis must be laid on the "deepening and broadening" of knowledge objectives, which are considered to be the most basic in the cognitive domain and obtained an average above 4 . It is also noteworthy that the average score in the category referred to as the "application of knowledge acquired in the course" (3.23) was the lowest of all the evaluated objectives.

Table 1. Pedagogical objectives of the course

\begin{tabular}{lc}
\hline \multicolumn{1}{c}{ Pedagogical Objectives } & Average \\
\hline Deepen their knowledge & 4.16 \\
\hline Identify their professional goals & 3.65 \\
\hline Plan actions of personal and professional development & 3.91 \\
\hline Enlarge systemic and integrated visions of management & 3.49 \\
\hline Develop/expand knowledge, skills and attitudes in the chosen emphasis & 4.29 \\
\hline Apply knowledge acquired in the course & 3.23 \\
\hline Aggregate systemic value to the chosen emphasis & 3.34 \\
\hline Consolidate integrated view of management & 3.56 \\
\hline Base the development of term paper & 3.26 \\
\hline
\end{tabular}

Regarding the course educational activities, the proposed activities in the classroom were given higher scores by the students (Table 2). This may be related to 
the professors' constant search for innovation of classroom practices in isolated initiatives.

Regarding the course educational activities, activities outside of the classroom have lower averages and the preliminary activity has the worst average among the educational activities. The percentage of utilization of offered extra-curricular activities is also considered very low (Table 3). In this case, there is a great opportunity to improve the learning experience beyond the classroom limits.

Table 2. Educational activities

\begin{tabular}{lc}
\hline \multicolumn{1}{c}{ Educational Activity } & Average \\
\hline Preliminary Activity & 3.86 \\
\hline Activities in the Classroom & 4.49 \\
\hline Learning Check & 4.11 \\
\hline
\end{tabular}

Table 3. Extra-curricular activities

\begin{tabular}{lc}
\hline \multicolumn{1}{c}{ Extracurricular activity } & \% of utilization \\
\hline Individual technical support & $23.8 \%$ \\
\hline Advice of curriculum customization & $46.3 \%$ \\
\hline Individual Counseling of Career Management & $27.5 \%$ \\
\hline Lecture of Career Management & $35.0 \%$ \\
\hline
\end{tabular}

Dealing with the completion objectives intended for the course, all of them may also be considered accomplished since the lower average was 3.85 on a 5-point scale (Table 4). Again, it is observed that the item, "able to apply management tools," is the one that had the lowest average. The overall average of the course results was 4.02 .

Table 4. Results of the course

\begin{tabular}{lc}
\hline \multicolumn{1}{c}{ Results } & Average \\
\hline Larger systemic and integrated view of management & 4.18 \\
\hline Becoming more skilled in management practice & 4.19 \\
\hline Applying management tools & 3,85 \\
\hline Developing the ability to work in teams & 3.95 \\
\hline Acquiring greater ability to adapt to situations and diverse groups & 4.00 \\
\hline Learning by sharing concepts, practices and information & 3.99 \\
\hline
\end{tabular}




\section{Qualitative Results}

Based on the analysis of the results obtained, six categories were identified that represent the challenges of contemporary marketing:

1. Customer and market knowledge: knowledge and relationship with customers and prospects, in order to better understand their needs

2. Brand excellence: pursuit of the excellence of a brand promise, materializing a way of thinking and doing business to boost confidence and admiration in all business relationships

3. Commercial: planning the sale of products and services, aiming at higher profitability and productivity for the enterprise

4. Digital: use of new technologies for the design and implementation of marketing strategies

5. Individual manager features: the set of an individual's skills and attitudes

6. Business management: aspects related to the systemic vision and strategic direction of the organization

The challenges related specifically to the marketing area of expertise could be grouped into the following categories: customer and market knowledge -1 . brand excellence -2 . and commercial -3 . where there are the main challenges in the respondent's view. It is noteworthy that the challenges specifically related to the development of the value proposition, or the solution to the client, were not mentioned.

Other issues beyond marketing were also identified, and they generated three categories: one category related to the field of technology (Digital -4 ), one category related to personal development (Individual manager features - 5), and one related to the strategic and systemic view of the organization category (Business management -6 ). Aspects related to the strategic vision of the organization and personal characteristics are expected, and, in the face of environmental changes resulting from technological development, those relating to technology also become part of the agenda of the respondents.

\section{Discussion}

The results from the quantitative approach used in this study demonstrate that the course, despite receiving a good evaluation, has many opportunities for improvement, especially regarding the methodological procedures through the identification and implementation of practices that extend to the applicability of 
the content, as well as the expansion the of the effectiveness of activities that take place outside of the classroom.

The qualitative approach shows that the group of marketing executives was concerned with aspects related to business management, systemic and strategic vision of the organization, customers' knowledge, and market understanding. This can be explained by the fact that the respondents occupy strategic positions in their organizations and are executives responsible for marketing. Therefore, to develop the main strategy, it is important to take a more strategic view of marketing and its integration with other areas of the company. Since, in general, these executives lead the process of implementation and monitoring marketing strategies, the concern with the development of individual characteristics can be seen, such as leadership, negotiation, and communication. The aspects related to brand management were also mentioned. Regarding the aspects related to marketing and technological environment, the executives did not mention them at all. This can be explained by the fact that the aspects related to the marketing of products and the digital environment may have been considered in the implementation of the marketing strategy.

The individual characteristics and business management are more intensely scrutinized by the executives than by the professors, which can be related to the position that the executives hold in the organization, associated with their responsibilities.

Among the marketing professors, aspects related to customer knowledge, market understanding, and excellence of the brand were pointed out and they coincided with the executive vision. This reinforces the notion that these areas have the most important challenges linked to contemporary management markets. The professors also mentioned aspects related to marketing and the technological environment, or digital with relative importance. This can be explained by the fact that the professors act more specifically on issues related to the implementation of the marketing strategy.

The results of the qualitative stage indicate a possibility for improvement in the review of the contents discussed in the course in order to make them more up to date and adhering to professional practice. This idea combines with the results of the quantitative stage, which pointed to the need for a methodological procedure expansion that would enable the application of the contents discussed in class.

The competency-based curriculum was chosen to guide the process of the course reformulation, since in this approach, the focus on learning is not the only content, since the implementation of capacity is also crucial. The beginning 
of the process defined the competences profile to be formed by the course. This definition was based on the qualitative approach developed in this study, where the professors and marketing department executives pointed out today's main challenges in this area of expertise.

This profile was used as a reference for structuring the subjects of the marketing course both for the selection of the program content and for the definition of educational activities. The definition of disciplines follows the competence areas defined in the profile. The pedagogical objectives proposed for each of the disciplines aim to meet the detailed observable performance in the profile.

The goal was to incorporate the role of previous activities developed outside of the classroom into the methodological approach and educational activities of the course and to try to focus on the conceptual levelling; thus, leaving the approaches related to the application to be developed in the classroom. Also, the evaluation activity was modified, prioritizing issues related to the application of the content.

\section{Conclusions}

The lato sensu postgraduate courses have the challenge of always being aligned with trends and innovations regarding the content and the methodological practices. Especially in the specific management courses for marketing, following market trends is a key activity since the market is the proper object of the course. In addition, students are increasingly informed and familiar with technological devices that can be used as tools in the processes of teaching and learning.

The competency-based curriculum proved to be suitable for the process of the reformulation of the lato sensu postgraduate course in management, in the specific cycle of marketing, since it enabled a more focused approach to practice and application and, therefore, was more aligned with market trends.

The goal now is to expand this process for the entire course, as well as for other courses from the institution. In addition, the quantitative approach of this study will be applied annually in order to monitor the results of this review and sustain a continuous process of improvement. The qualitative approach will be applied every two years, in order to maintain the program contents. 


\section{References}

Bearden, W.O., and J.E. Teel. (1983). "Selected Determinants of Consumer Satisfaction and Complaint Reports.” Journal of Marketing Research 20 (1): 21-28.

Bednarski, Jules (1962). The Eidetic Reduction. Philosophy Today, 6(1), 14-24.

Bonwell, C.C., \& Eison, J.A. (1991). Active Learning: Creating Excitement in the Classroom. 1991 ASHE-ERIC Higher Education Reports. ERIC Clearinghouse on Higher Education, The George Washington University, One Dupont Circle, Suite 630, Washington.

Cortese, A.D. (2003). The critical role of higher education in creating a sustainable future. Planning for higher education, 31(3), 15-22.

Danciu, V. (2013). The future of marketing: an appropriate response to the environment changes. Theoretical and Applied Economics, 20(5), 33-52.

Fornell, C. 1992. "A National Customer Satisfaction Barometer: The Swedish Experience." Journal of Marketing 56 (1): 6-21.

Fornell, C., M.D. Johnson, E.W. Anderson, J. Cha, and B.E. Bryant. 1996. “The American Customer Satisfaction Index: Nature, Purpose, and Findings.” Journal of Marketing 60 (4): 7-18.

Gillies, A., \& Howard, J. (2003). Managing change in process and people: Combining a maturity model with a competency-based approach.

Gordon, D., \& Issenberg, S.B. (2003). Development of a competency-based neurology clerkship. Medical Education, 37, 484-485.

James, P. (2002). Discourses and practices of competency-based training: Implications for worker and practitioner identities. International Journal of Lifelong Education, 21, 369-391.

Kinser, K., \& Levy, D.C. (2005, Feb). The for-profit sector: US patterns and international echoes in higher education. Paper presented at the Program for Research on Private Higher Education. Albany, New York.

Kirp, D.L. (2009). Shakespeare, Einstein, and the bottom line: the marketing of higher education. Cambridge: Harvard University.

Kotler, P. (2000). Marketing management: the millennium edition. New Jersey: Prentice Hall.

Leeflang, P.S., Verhoef, P.C., Dahlström, P., \& Freundt, T. (2014). Challenges and solutions for marketing in a digital era. European Management Journal, 32(1), 1-12.

Levy, D.C. (2002, April). Unanticipated development: perspectives on private higher education's emerging roles. Paper presented at the meeting of Program for Research on Private Higher Education. Albany, New York.

Levy, D.C. (2003, March). How South Africa epitomizes the global surge in commercial private higher education. Paper presented at the meeting of Program for Research on Private Higher Education. Albany, New York.

Levy, D.C. (2004, January). The new institutionalism: mismatches with private higher education's global growth. Paper presented at the meeting of Program for Research on Private Higher Education. Albany, New York.

Levy, D.C. (2006). The unanticipated explosion: private higher education's global surge. Comparative Education Review 50 (2):217-240 
Levy, D.C. (2008, April). Access through private higher education: global patterns and Indian illustrations. Paper presented at the meeting of Program for Research on Private Higher Education. Albany, New York.

Maringe, F., \& Gibbs, P. (2009). Marketing higher education: theory and practice. London: Open University Press and McGraw-Hill Education.

Mertens, D.E. (2005). Research and evaluation in education and psychology: Integrating diversity with quantitative, qualitative, and mixed methods ( $2^{\text {nd }}$ ed.). Thousand Oaks, CA: Sage.

Moffitt, S., Dover, M., \& Tapscott, D. (2010). Wikibrands: reinventing your company in a customer-driven marketplace. New York: McGraw Hill Professional.

Pollock, Roy V.H.; Jefferson, Andy; Wick, Calhoun W. (2015) The Six Disciplines of Breakthrough Learning: How to Turn Training and Development into Business Results. John Wiley \& Sons, Inc., Hoboken, New Jersey.

Prince, M. (2004). Does active learning work? A review of the research. Journal of Engineering Education, 93(3), 223-231.

Ryan, M.P., \& Martens, G.G. (1989). Planning a college course: A guidebook for the graduate teaching assistant. Ann Arbor, MI: The National Center for Research to Improve Postsecondary Teaching and Learning, The University of Michigan

Schwandt, T. (2000). Three epistemological stances for qualitative inquiry: Interpretivism, hermeneutics, and social constructionism. In N.K. Denzin \& Y. Lincoln (Eds.), Handbook of qualitative research ( $2^{\text {nd }}$ ed.; pp. 189-214). Thousand Oaks, CA: Sage.

Seung Youn (Yonnie), C., Stepich, D., \& Cox, D. (2006). Building a Competency-Based Curriculum Architecture to Educate 21 $1^{\text {st }}$ Century Business Practitioners. Journal Of Education For Business, 81(6), 307-314.

Stukalina, Y. (2012). Addressing service quality issues in higher education: the educational environment evaluation from the students' perspective. Technological \& Economic Development Of Economy, 18(1), 84-98. doi:10.3846/20294913.2012.658099

Stewart, D.W. and Shamdasani, P.N., (1991). Focus Groups, Sage Publications, Newbury Park, CA.

Wan, V.C., Lee, C.M. \& Lee, S.Y., (2007). Understanding consumer attitudes on edible films and coatings: Focus group findings, Journal of Sensory Studies, 22(20). 353-366.

Wick, C.W., Pollock, R.V., Jefferson, A., \& Flanagan, R.D. (2010). The six disciplines of breakthrough learning. San Francisco, CA: Pfeiffer. 